\title{
Applying Theory-Driven Approaches to Understanding and Modifying Clinicians' Behavior: What Do We Know?
}

\author{
Marthew B. Perlkins, M。D。, M。B.A. \\ Peter S. Jensem, M.D. \\ James Jaccard, Ph.D. \\ Peter Golllwitzer, Ph.D. \\ Gabrielle Oetringem, Ph.D. \\ Elizabeth Pappadopullos, Ph.D. \\ Kimberly E.Hoægwood, Ph.D.
}

\begin{abstract}
Objective: Despite major recent research advances, large gaps exist between accepted mental health knowledge and clinicians' real-world practices. Although hundreds of studies have successfully utilized basic behavioral science theories to understand, predict, and change patients' health behaviors, the extent to which these theories-most notably the theory of reasoned action (TRA) and its extension, the theory of planned behavior (TPB) - have been applied to understand and change clinician behavior is unclear. This article reviews the application of theory-driven approaches to understanding and changing clinician behaviors. Methods: MEDLINE and PsycINFO databases were searched, along with bibliographies, textbooks on health behavior or public health, and references from experts, to find article titles that describe theory-driven approaches (TRA or TPB) to understanding and modifying health professionals' behavior. Results: A total of 19 articles that detailed 20 studies described the use of TRA or TPB and clinicians' behavior. Eight articles describe the use of TRA or TPB with physicians, four relate to nurses, three relate to pharmacists, and two relate to health workers. Only two articles applied TRA or TPB to mental health clinicians. The body of work shows that different constructs of TRA or TPB predict intentions and behavior among different groups of clinicians and for different behaviors and guidelines. Conclusions: The number of studies on this topic is extremely limited, but they offer a rationale and a direction for future research as well as a theoretical basis for increasing the specificity and efficiency of clinician-targeted interventions.
\end{abstract}

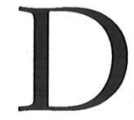
espite substantial investments in research, dissemination, and advocacy, a huge gap exists between what is known about effective mental health services and what is done in real-world practice $(1,2)$. For example, the Surgeon General's Report on Mental Health identified a range of evidence-based treatments for individuals with mental illness, including specific therapies, medication algorithms, and comprehensive rehabilitation programs. Yet well-documented, proven interventions have limited penetration into the public mental health system (3). And despite strategies to address these problems, such as the development and dissemination of practice guidelines, reviews of the impact of disseminating these interventions indicate that when the interventions are provided without further support (for example, only through continuing medical education conferences or mailings of unsolicited materials), the interventions are usually not sufficient to bring about changes in clinical practice $(4,5)$.

Recent research has begun to examine the strategies necessary to facilitate actual implementation of evidence-based practices, often drawing upon teaching methods derived from the adult educational literature. This research has shown that the most effective strategies take advantage of methods such as using
Dr. Perkins, Dr. Jensen, Dr. Pappadopulos, and Dr. Hoagwood are affiliated with the Department of Child Psychiatry, Center for the Advancement of Children's Mental Health, Columbia University, New York City. Dr. Jaccard is with the Department of Psychology, Florida International University, Miami. Dr. Gollwitzer and Dr. Oettingen are with the Department of Psychology, New York University, New York City. Send correspondence to Dr. Jensen at the Department of Child Psychiatry, Center for the Advancement of Children's Mental Health, Columbia University, 1051 Riverside Dr., Unit 78, New York, NY 10032 (e-mail:pj131@columbia.edu). 
self-directed curricula and smallgroup interactions, helping learners assess the discrepancy between what they ought to know or do and what they know or do, and providing opportunities to try out an innovation before putting it into practice (6). In addition, a growing body of literature on changing physicians' behavior indicates that multipronged approaches-particularly those involving sustained interactions with physician-experts and hands-on practice in the new behavior, for example, academic detailing-are most likely to lead to behavioral change (7-11).

Although studies of changing clinicians' behavior are relatively limited, there is a very large body of literature on changing the behavior of patients and consumers. Well-studied theories related to changing an individual's behavior include the social cognitive theory (12), the theory of reasoned action (13), the theory of planned behavior (14), and the health belief model (15). The transtheoretical model, also known as stages of change, addresses an individual's readiness to change (16). Rogers' (17) diffusion of innovations theory describes factors that affect the adoption of a given practice or behavior. Experts agree on factors common to behavior change, many of which are fundamental to the most widely researched of these theories, the theory of planned behavior (TPB) and the theory of reasoned action (TRA) $(18,19)$. Given the predominance of TRA and TPB in studies of patients' behavior, this article aims to briefly review TRA and TPB, examine theory-based applications to clinicians' behavior, and provide directions for further study.

\section{Theory of reasoned action and theory of planned behavior}

TRA and TPB build upon the simple proposition that many behaviors that an individual performs can be predicted simply from a person's intentions to perform those behaviorsthat is, that people do what they intend to do and do not do what they do not intend to do. Such intentions are called behavioral intentions. In general, behavioral intentions tend to be

\section{IFigure 1}

Core relationships between the primary determinants of behavioral intentions, behavioral intentions, and behavior in the theory of reasoned action and the theory of planned behavior

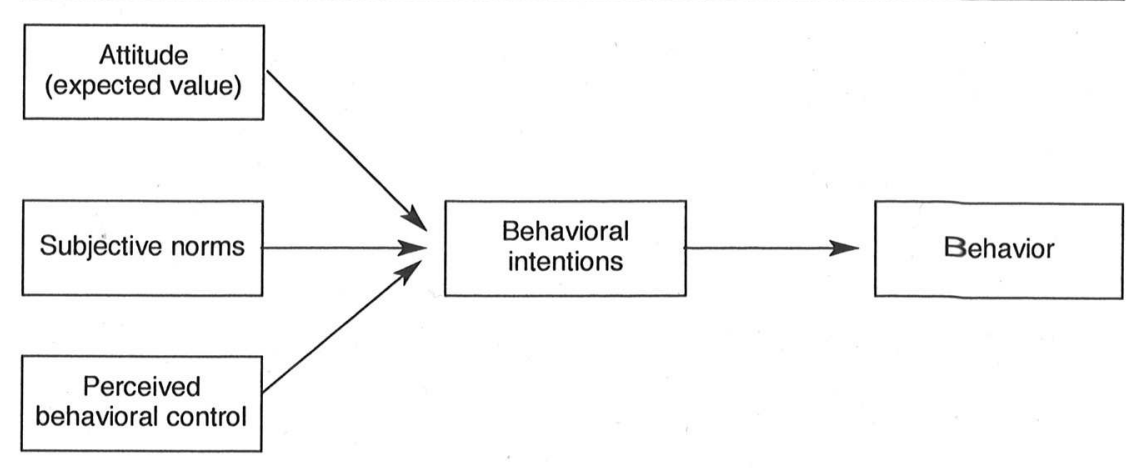

good predictors of future behavior, although there are scenarios in which this is not the case $(13,20-23)$.

TRA and TPB emphasize two core variables that influence the strength of an intention: the expected value of behavioral performance and subjective norms. TPB is an extension of TRA that also measures self-efficacy beliefs, also known as perceived behavioral control

The first factor, expected value, refers to an individual's perceptions about the advantages and disadvantages of performing a particular behavior. The perceived outcomes of performing a particular behavior are known as behavioral beliefs. A behavioral belief is a perceived association between performing the behavior and the occurrence of some consequence or outcome.

The second factor is subjective norms, which is made up of two components. The first component is normative beliefs about the behavior, or the beliefs that relate to an individual's perception of what important others (referents) think he or she should do in regard to this behavior or situation. The second is the individual's degree of motivation to comply with the different referents.

The third factor that may influence an individual's intentions to perform a behavior is perceived behavioral control, or self-efficacy beliefs (24). Perceived behavioral control refers to the individual's perception that he or she can carry out the behavior and overcome the obstacles that stand in the way of implementing it. Even though a behavior may have a positive expected value and even though the individual may have positive normative beliefs, the individual may not perform a given behavior if he or she thinks it cannot be done.

The core relationships between behavioral intentions and behavior and the primary determinants of behavioral intentions are indicated in Figure 1. Two features of this framework should be emphasized. First, the three core predictors of behavioral intentions are presumed to be the primary determinants of intentions. Other constructs-such as personality, environmental, and demographic variables-may influence behavioral intentions, but in this model they do so through their influence on these primary variables. Second, the framework maintains that the relative importance of the constructs in influencing behavioral intentions can differ among persons or in populations. For some individuals, normative influences may be the primary determinant of the behavioral intentions to perform a behavior, whereas for others expected values may be of primary importance.

Hundreds of studies support the utility of the main constructs of the framework presented here, and TRA and TPB models are considered to be at the forefront in the field of social science and understanding behavior $(13,18)$. Given the scientific support for these models of behavior change in many populations (principally pa- 
tient groups) and the need for more effective approaches for changing clinicians' behavior, we reviewed the literature to determine the extent to which these models have been applied to health care providers, including mental health care providers. In addition, we have outlined areas for future research in which these models could be applied to better understand clinicians' behavior and facilitate the adoption of evidence-based practices.

\section{Methods}

We searched MEDLINE (January 1966 to January 2006) and PsycINFO (1872 to January 2006), with the goal of finding article titles that describe theory-driven approaches to understanding and modifying health professionals' behavior. MeSH terms included planned behavior, intention, health behavior, and health personnel attitudes. Additional key word searches included theory of reasoned action and theory of planned behavior. Other candidate articles were identified by reviewing bibliographies of articles from the search. We reviewed only those articles that applied TRA or TPB to the behavior of health professionals (nonpatient and nonconsumer).

\section{Results}

A total of 19 articles describe 20 studies detailing the use of TRA or TPB and their effect on clinicians' behavior. Eight articles describe the use of TRA or TPB with physicians, four articles relate to nurses, three articles relate to pharmacists, and two articles relate to health care workers. Only two articles applied TRA or TPB to mental health clinicians.

\section{General bealth care providers}

Among physicians, the earliest study involving TRA or TPB was conducted in 1992 by Kinket and colleagues (25), who examined 49 general practitioners to determine how their attitudes, subjective norms, and perceived behavioral control were related to their intentions and self-reported behavior. By using the theory of planned behavior, Kinket and colleagues determined that attitudes were the strongest predictor of inten- tions, explaining $27 \%$ of the variability; however, social norms and behavioral control did not increase the predictive power of the model. [A table displaying all of the studies, constructs utilized, and relevant details is available as an online supplement to our article at ps.psychiatryonline. org.] Attitudes were also found to be the strongest predictor of intentions in Limbert and Lamb's (26) study of physicians' use of a guideline for antibiotics. However, Limbert and Lamb found that subjective norms were the strongest predictor of junior physicians' use of an asthma management guideline.

Other studies of physicians' behavior (27-32) demonstrated important variations in results, depending on the specific behavior being studied and on the specific group of physicians. For example, Gaither and colleagues (28) demonstrated that social norms were the predominant determinant of use of drug information by physicians in health maintenance organizations, and Bunce and Birdi (29) found social norms to be the strongest predictor of doctors' intention to request hospital autopsies. In contrast, Millstein (30) found perceived behavioral control to be the strongest predictor of a primary care physician's intention to educate adolescents about sexually transmitted diseases. And in other instances attitudes have been shown to be the strongest predictor of intentions (zero-order correlation between attitudes and intentions of .57) (31). [See table available as an online supplement at ps.psychiatryonline.org.]

In the field of nursing, four studies examined the extent to which TRA or TPB predicted nursing behaviors, such as care for HIV-positive patients (33), care for patients with chronic pain (34), and the delivery of smoking cessation advice $(35,36)$. As with the physician studies, TRA or TPB factors, such as attitudes, subjective norms, and perceived behavioral control, were strong predictors of nursing behavior in these various studies, depending on the study sample and particular behavior in question. [See table available as an online supplement at ps.psychiatryonline.org.]

TPB has also been utilized to ex- amine the behavior of other health care professionals. For example, two studies examined pharmacists' practices by using TPB constructs $(37,38)$, and another used TPB components to develop a causal model to address the delivery of pharmaceutical care (39). As with the studies of physicians and nurses, these studies of pharmacists also suggested that the constructs of the model and the constructs' correlation to intentions and behavior varied on the basis of the particular behavior and the group of pharmacists being studied (37-39). Studies of other health care workers, such as laboratory technicians, show similar results $(40,41)$.

\section{Mental bealth providers}

Of the 19 identified articles detailing 20 studies, only two studies were identified that used a theoretical model to understand mental health providers' intentions to perform a particular behavior. Meissen and colleagues (42) used TRA to assess the intentions of 168 clinical psychology or social work graduate students to refer patients to self-help groups. Attitudes toward self-help groups proved to be the strongest predictor of intentions. Additionally, personal experiences with self-help groups correlated with intentions.

The other study in the field of mental health was a dissertation that used TPB to examine how social workers use DSM-IV (43). Among 249 social workers, independent predictors for intentions to use DSM-IV for client assessment and treatment were attitudes related to increased credibility and competence, ability or self-efficacy to apply DSM-IV (confidence, training, and facility), and a negative influence (correlation) of mental health workers, such as psychiatrists and other social workers.

\section{Discussion}

Overall, this limited collection of studies $(\mathrm{N}=20)$ provides support for the applicability of TRA and TPB models for understanding clinicians' behavior. The small number of studies is striking and unfortunate, given the current climate encouraging the adoption of evidence-based care and the relative lack of success in most ef- 
forts to modify clinician behavior (4-6,44-47). The discrepancy between what is known and what clinicians actually do in practice calls for more studies to understand clinicians' behavior and, most especially, studies of how to promote the adoption of new behaviors.

The few studies available and reviewed here vary widely in their application of the theoretical model. Some followed the strict recommendations set by the developers of TRA and TPB, whereas others picked and chose components for their study. Although this is understandable in order to make a study feasible, it also makes comparing and extrapolating the results difficult.

An additional concern about many of the studies is that only intentions were measured. Only eight of the 18 articles included a self-report of actual behavior and measured the correlation between the constructs, intentions, and behavior. Remarkably, only one study, an examination of Thai obstetricians' use of five antibiotic prophylaxis guidelines, actually measured behavior as determined from the medical record (32). This study did not, however, evaluate the correlation between TPB constructs and actual behavior, which is where the theory should have greatest application for future interventions with the physicians.

Of note, the utilization of TRA or TPB with clinicians, in most cases, has focused on trying to understand clinicians' behavior, rather than extending the study to understand how to change clinicians' behavior. Only the study by Jenner and colleagues (41) identified specific barriers related to TRA or TPB that affected the behaviors of health care workers and then used the results to provide an immediate action plan that could be implemented and tested to evaluate whether behavior had changed. Even though the theories of TRA and TPB have rarely been applied to change health care providers' behaviors, there are many examples in which these approaches have been used to help change patients' behaviors (48-52). Given the solid empirical underpinnings of the theories of TRA and TPB, there is reason for cautious optimism that effective strategies based on these theories might yield similar results with health care providers.

\section{Future directions}

How could TRA and TPB approaches be utilized in mental health? Take the example of a treatment team leader working to implement guidelines for the treatment of schizophrenia. One of the specific behavioral goals of the guidelines may be to improve psychiatrists' prescribing practices relating to the duration of treatment and the dosage of a particular medication to establish an adequate trial.

The first step would be to understand the key beliefs, attitudes, social norms, and perceived behavioral control issues that physicians hold in relation to this specific behavior required by the guidelines. Armed with such information, the treatment team leader could better address the educational challenges (barriers to TRA or TPB) of specific physicians on the basis of their individual attitudes, social norms, and perceived behavioral control. For physicians with high behavioral control and negative attitudes toward implementing these guidelines (goal behavior), an intervention might focus on their attitudes, assuming that there was a strong correlation between attitudes and intentions or behavior. This might include a continuing medical education course that addresses the science behind the guidelines and the goal behavior as well as the possible benefits to patients and the facility. The goal would be to deliver an intervention that will impact a mediator that may result in a change in behavior.

For physicians who already have very positive attitudes toward this goal behavior but have low levels of perceived behavioral control, the previously described intervention would likely provide only modest benefits. For this group it would be necessary to modify the intervention to problem-solve with the physicians to enhance their self-efficacy and perceived behavioral control in actually applying guideline. For example, focusing on skill development rather than attitudes may be more helpful.

\section{Behavior change}

\section{in the larger context}

Although constructs of TRA and TPB that pertain to persons' beliefs and attitudes may help us to understand behavior, it does not necessarily follow that this understanding will lead to the knowledge of how to change these beliefs. Here, much research is needed. Moreover, even if one is able to change the attitudes in question, thereby increasing intentions, behavior change does not invariably follow.

Even with good intentions obstacles may interfere with ultimately carrying out the target. As a consequence, support is necessary even when intentions are high. Toolkits can prove useful, to the extent that they address obstacles encountered en route to behavioral performance. The National Evidence-Based Practices Project has developed toolkits to help states adopt six different evidencebased mental health practices. The toolkits address the need to enhance motivation for change, provide appropriate resources, increase skill development, and remove constraints in the environment (53).

Other reviews of changing clinicians' behavior have focused more broadly on factors relevant to effective implementation of practice guidelines, including barriers and incentives to change (54-57). Grol and Wensing (57) proposed that barriers and incentives be addressed at six levels: the innovation itself, the individual professional, the patient, the social context, the organizational context, and the economic and political context. Thus, although TRA and TPB may be powerful models for new research, other theoretical models are likely to be needed, including multilevel approaches that address organizational, economic, and political factors, as well as individual factors. Behavioral, social influence, marketing, and organizational theories all deliver valuable perspectives to the challenge of changing clinicians' behavior.

Ultimately, individual, social, economic, political, and organizational factors coalesce to influence individual clinicians who perform specific clinical behaviors. TRA and TPB 


\section{IFlgure 2}

Multipronged approach representing points of intervention and possible barriers within the framework of the theory of reasoned action and the theory of planned behavior

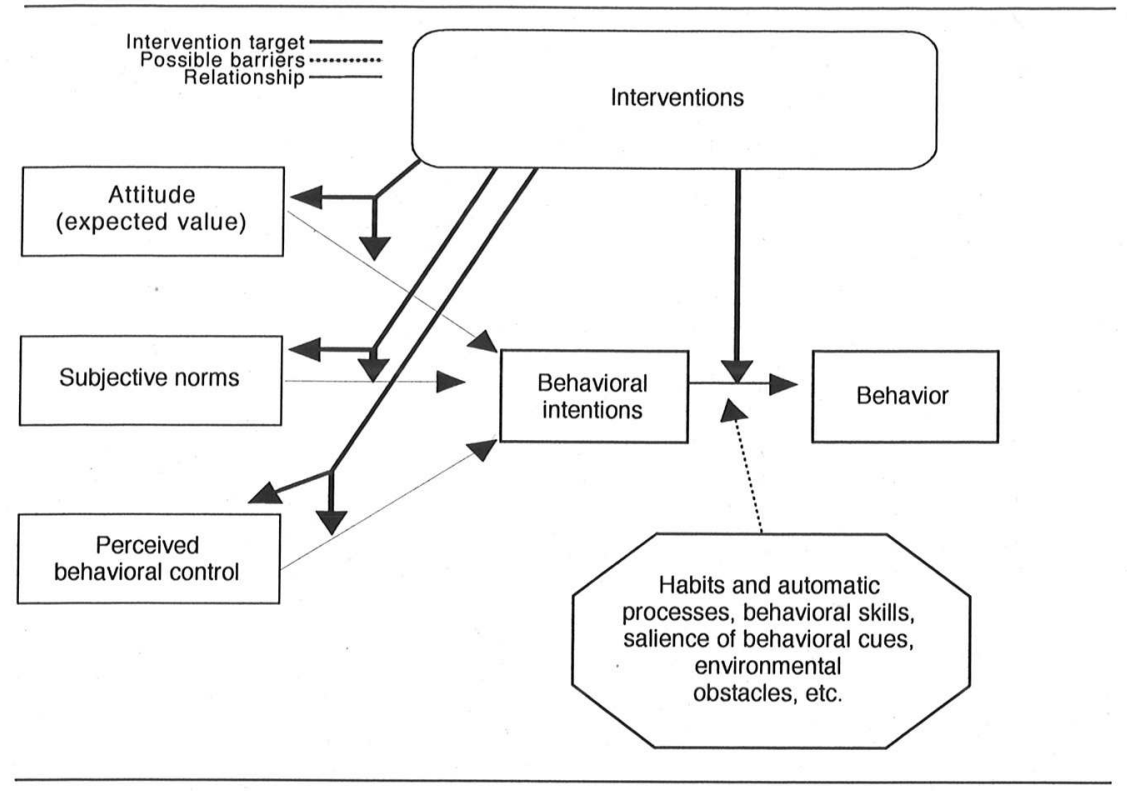

models can inform many, but not all, aspects of study designs and interventions focusing on changing clinicians' behavior. Figure 2 represents a more sophisticated understanding of the various influences, including barriers, that affect individual behaviors and points that may also be targets for intervention. The figure identifies the different target areas for interventions and addresses the obstacles that get in the way even after behavioral intentions are formed. It is important to note that arrows are drawn not only to the constructs-for example, attitudes, norms, and perceived control-but also to the arrows representing the impact these constructs have on intentions and ultimate behavior. Thus it is possible to intervene by changing the relative importance or impact of the construct without actually changing the construct itself. An example might be an intervention that encourages individuals to reflect on the positive aspects of a given behavior (attitudes) or to ignore what important others (referents) expect (that is, norms) if those norms interfere with the behavior. One can thus influence the relative impact of the three constructs on individuals' intentions to perform a given behavior without actually chang- ing the constructs themselves.

The multipronged approach represented by Figure 2 would be carefully designed and informed by the application of TRA or TPB (to determine relevant mediators to target) and by effective strategies for overcoming obstacles and translating intentions into behavior. New lines of research emphasize planning for and anticipating obstacles and then assisting the clinicians in forming strategies to address the obstacles en route to behavioral performance. This line of evidence suggests that actual behavior performance can be greatly enhanced, even when intentions are high $(58,59)$.

The application of TRA and TPB models and these new types of planning strategies are currently being investigated in two studies funded by the National Institute of Mental Health (60,61). For example, Jensen's (61) study applied TRA and TPB in the assessment of physicians' attitudes, social norms, and self-efficacy with regard to Treatment Recommendations for the Use of Antipsychotics for Aggressive Youth. Then the study examined three separate interventions to determine their impact on the mediating constructs of TRA and TPB. The interventions themselves were based on the latest sci- ence. One of the interventions incorporated a planning strategy that has proven to enhance and maintain the translation of desired intentions to actual behavior; thus this intervention targeted not only the three mediators that impacted intentions but also the step between intentions and behavior. At multiple phases of this study, TRA and TPB constructs and behavior and the interventions' effect on both the intervening constructs and the behaviors were measured.

Although this type of intervention could be costly, administratively complex, and unpopular among clinicians, technologic advances may enable cost-effective and user-friendly interventions to be customized to the needs of individual clinicians. For example, such an intervention might be done on the basis of an online preintervention or computer-based surveys completed by clinicians to ascertain their attitudes, beliefs, concerns, and learning needs, followed by delivery of specific information modules based on the particular needs identified by each clinician.

\section{Conclusions}

The business of mental health is behavior change. Just as therapists seek to understand their patients through a thorough diagnostic process before recommending or applying appropriate treatment, individuals charged with improving clinicians' behavior must do the same. Understanding clinicians' attitudes, subjective norms, and perceived behavioral control and providing the necessary support are the keys to developing an intervention that is most likely to impact behavior. Utilizing the theoretical basis of the studies that have been completed, mental health researchers, clinicians, and policy makers are uniquely poised to be leaders in innovative and thoughtful interventions that are based on the best science to understand and change clinicians' behavior.

\section{Acknowledgments and disclosures}

The authors report no competing interests.

\section{References}

1. Ganju V: Implementation of evidencebased practices in state mental health sys- 
tems: implications for research and effectiveness studies. Schizophrenia Bulletin 29:125-131, 2003

2. Drake RE, Goldman HH, Leff HS, et al Implementing evidence-based practices in routine mental health service settings. Psychiatric Services 52:179-182, 2001

3. Mental Health: A Report of the Surgeon General. Washington, DC, Department of Health and Human Services, US Public Health Service, 1999

4. Davis DA, Taylor-Vaisey A: Translating guidelines into practice: a systematic review of theoretical concepts, practical experience, and research evidence in the adoption of clinical practice guidelines. Canadian Medical Association Journal 157:408416, 1997

5. Oxman AD, Thomson MA, Davis DA, et al No magic bullets: a systematic review of 102 trials of interventions to improve professional practice. Canadian Medical Association Journal 153:1423-1431, 1995

6. Fox RD, Bennett NL: Continuing medical education: learning and change: implications for continuing medical education. British Medical Journal 316:466-468, 1998

7. Katon W, Von Korff M, Lin E, et al: Collaborative management to achieve treatment guidelines: impact on depression in primary care. JAMA 273:1026-1031, 1995

8. Katon W, Robinson P, Von Korff M, et al: A multifaceted intervention to improve treatment of depression in primary care Archives of General Psychiatry 53:924-932 1996

9. Rost K, Nutting PA, Smith J, et al: Designing and implementing a primary care intervention trial to improve the quality and outcome of care for major depression. General Hospital Psychiatry 22:66-77, 2000

10. Soumerai SB, Avorn J: Principles of educational outreach ("academic detailing") to improve clinical decision making. JAMA 263:549-556, 1990

11. Soumerai SB: Principles and uses of academic detailing to improve the management of psychiatric disorders. International Journal of Psychiatry in Medicine 28:8196, 1998

12. Bandura A: Social Foundations of Thought and Action: A Social Cognitive Theory. Englewood Cliffs, NJ, Prentice Hall, 1986

13. Ajzen I, Fishbein M: Understanding Attitudes and Predicting Social Behavior. Englewood Cliffs, NJ, Prentice Hall, 1980

14. Ajzen I: The theory of planned behavior. Organizational Behavior and Human Decision Processes 50:179-211, 1991

15. Janz NK, Becker MH: The health belief model: a decade later. Health Education Quarterly 11:1-47, 1984

16. Prochaska JO, DiClemente CC: Stages and processes of self-change of smoking: toward an integrated model of change. Journal of Consulting and Clinical Psychology 51:390-395, 1983
17. Rogers EM: Lessons for guidelines from the diffusion of innovation. Joint Commission Journal on Quality Improvement 21:324-328, 1995

18. Armitage CJ, Conner M: Efficacy of the Theory of Planned Behaviour: a meta-analytic review. British Journal of Social Psychology 40:471-499, 2001

19. Fishbein, M: Developing effective behavior change intervention: some lessons learned from behavioral research, in Reviewing the Behavioral Science Knowledge Base on Technology Transfer. Edited by Backer TE, David SL, Saucy G. Rockville, Md, National Institute on Drug Abuse, 1995

20. Jaccard J: A theoretical analysis of selected factors important to health education strategies. Health Education Monographs 3:152-167, 1975

21. Jaccard J, Wood G: An idiothetic analysis of attitude-behavior models. Advances in Consumer Research 13:601-605, 1985

22. Jaccard J, Litardo H, Wan C: Subjective culture: social psychological models of be havior, in Social Psychology and Cultural Context. Edited by Adamopolis J, Kashima Y. Newbury Park, Calif, Sage, 1999

23. Fishbein M, Ajzen I: Belief, Attitude, Intention and Behavior: An Introduction to Theory and Research. Reading, Mass, Addison-Wesley, 1975

24. Bandura A: Social Learning Theory. Englewood Cliffs, NJ, Prentice Hall, 1977

25. Kinket B, Paans L, Verplanken B: Patien education by general practitioners: application of the theory of planned behavior [in Dutch]. Gedrag and Gezondheid: Tijdschrift voor Psychologie and Gezondheid 20:187-195, 1992

26. Limbert C, Lamb R: Doctors' use of clinical guidelines: two applications of the Theory of Planned Behaviour. Psychology, Health and Medicine 7:301 $\rightarrow 310,2002$

27. Taylor VM, Montano DE, Koepsell T: Use of screening mammography by general internists. Cancer Detection and Prevention 18:455-462, 1994

28. Gaither CA, Bagozzi RP, Ascione FJ, et al A reasoned action approach to physicians utilization of drug information sources Pharmaceutical Research 13:1291-1298, 1996

29. Bunce D, Birdi KS: The theory of reasoned action and theory of planned behaviour as a function of job control. British Journal of Health Psychology 3:265-275, 1998

30. Millstein SG: Utility of the theories of reasoned action and planned behavior for predicting physician behavior: a prospective analysis. Health Psychology 15:398-402, 1996

31. Walker AE, Grimshaw JM, Armstrong EM Salient beliefs and intentions to prescribe antibiotics for patients with a sore throat. British Journal of Health Psychology 6:347-360, 2001

32. Liabsuetrakul T, Chongsuvivatwong V
Lumbiganon $\mathrm{P}$, et al: Obstetricians' attitudes, subjective norms, perceived controls, and intentions on antibiotic prophy laxis in caesarean section. Social Science and Medicine 57:1665-1674, 2003

33. Laschinger HS, Goldenberg D: Attitudes of practicing nurses as predictors of intended care behavior with persons who are HIV positive: testing the Ajzen-Fishbein theory of reasoned action. Research in Nursing and Health 16:441-450, 1993

34. Edwards HE, Nash RE, Najman JM, et al Determinants of nurses' intention to administer opioids for pain relief. Nursing and Health Sciences 3:149-159, 2001

35. McCarty MC, Hennrikus DJ, Lando HA, et al: Nurses' attitudes concerning the delivery of brief cessation advice to hospitalized smokers. Preventive Medicine: An International Journal Devoted to Practice and Theory 33:674-681, 2001

36. Puffer S, Rashidian A: Practice nurses' intentions to use clinical guidelines. Journal of Advanced Nursing 47:500 -509, 2004

37. Walker A, Watson M, Grimshaw J, et al: Applying the theory of planned behaviour to pharmacists' beliefs and intentions about the treatment of vaginal candidiasis with non-prescription medicines. Family Practice 21:670-676, 2004

38. Mashburn JH: Using the Theory of Planned Behavior to predict Texas community pharmacists' willingness to provide sterile syringes to known or suspected intravenous drug users. Dissertation $\mathrm{Ab}$ stracts International: Section B: Sciences and Engineering 64:6034, 2004

39. Farris KB, Schopflocher DP: Between intention and behavior: an application of community pharmacists' assessment of pharmaceutical care. Social Science and Medicine 49:55-66, 1999

40. Levin PF: Test of the Fishbein and Ajzen models as predictors of health care workers' glove use. Research in Nursing and Health 22:295-307, 1999

41. Jenner EA, Watson PWB, Miller L, et al: Explaining hand hygiene practice: an extended application of the Theory of Planned Behaviour. Psychology, Health and Medicine 7:311-326, 2002

42. Meissen GJ, Mason WC, Gleason DF: Understanding the attitudes and intentions of future professionals toward self-help. American Journal of Community Psychology 19:699-714, 1991

43. Klaybor GR: An application of the Theory of Planned Behavior on clinical social workers' utilization of the DSM-IV: an exploratory. Dissertation Abstracts International Section A 59:2720, 1999

44. Bauer MS: A review of quantitative studies of adherence to mental health clinical practice guidelines. Harvard Review of Psychiatry 10:138-153, 2002

45. Azocar F, Cuffel B, Goldman W, et al: The impact of evidence-based guideline dissemination for the assessment and treatment of major depression in a managed behavioral health care organization. Journal of 
Behavioral Health Services and Research 30:109-118, 2003

46. Udomratn P, Srisurapanont M: Impact on Thai psychiatrists of passive dissemination of a clinical practice guideline on prescribing attitudes in treatment-resistant schizo phrenia. Neuropsychobiology 45:186-190 2002

47. Cabana M, Rand C, Powe NR, et al: Why don't physicians follow clinical practice guidelines? JAMA 282:1458-1465, 1999

48. Jemmott JB, Jemmott LS, Fong GT: Abstinence and safer sex HIV risk-reduction interventions for African American adoles cents: a randomized controlled trial. JAMA 279:1529-1536, 1998

49. Jemmott JB, Jemmott LS, Braverman PK et al: HIV/STD risk reduction interventions for African American and Latino adolescent girls at an adolescent medicine clinic a randomized controlled trial. Archives of Pediatrics and Adolescent Medicine 159 440-449, 2005

50. Bryan AD, Aiken LS, West SG: Increasing condom use: evaluation of a theory-based intervention to prevent sexually transmitted diseases in young women. Health Psychology 15:371 -382, 1996
51. Fisher JD, Cronman DH, Osborn CY, et al: Clinician-initiated HIV risk reduction intervention for HIV-positive persons: formative research, acceptability, and fidelity of the options project. Journal of Acquired Immune Deficiency Syndromes 37(suppl): S78-S87, 2004

52. Fisher JD, Fisher WA, Cornman DH, et al: Clinician-delivered intervention during routine clinical care reduces unprotected sexual behavior among HIV-infected patients. Journal of Acquired Immune Deficiency Syndromes 41:44-52, 2006

53. Drake RE, Torrey WC, McHugo GJ: Strategies for implementing evidencebased practices in routine mental health settings. Evidence-Based Mental Health 6:6-7, 2003

54. Grol R, Grimshaw J: From best evidence to best practice: effective implementation of change in patients' care. Lancet 362:12251230, 2003

55. Grol R: Changing physicians' competence and performance: finding the balance between the individual and the organization. Journal of Continuing Education in the Health Professions 22:244-251, 2002

56. Grimshaw JM, Eccles MP, Walker AE, et al: Changing physicians' behavior: what works and thoughts on getting more things to work. Journal of Continuing Education in the Health Professions 22:237-243, 2002

57. Grol R, Wensing M: What drives change? Barriers to and incentives for achieving evidenced-based practice. Medical Journal of Australia 180:S57-S60, 2004

58. Gollwitzer PM, Bayer U, McCulloch K: The control of the unwanted, in The New Unconscious. Edited by Hassin R, Uleman J, Bargh JA. Oxford, United Kingdom, Oxford University Press, 2005

59. Sheeran P, Webb TL, Gollwitzer, PM: The interplay between goal intentions and implementation intentions. Personality and Social Psychology Bulletin 31:87, 2005

60. Bickman L: Implementing feedback interventions to improve outcomes. Computer Retrieval of Information on Scientific Projects. Available at http://crisp.cit.nih. gov/crisp/crisp_query.generate_screen. Accessed Oct 2005

61. Jensen PS: A theory-based intervention to change physician behavior. Computer Retrieval of Information on Scientific Projects. Available at http://crisp.cit.nih.gov/ crisp/crisp_query.generate_screen. Accessed Oct 2005 